\title{
A Twisted Uterine Mass - Rare Tale
}

\author{
Sakshi Sharma ${ }^{1}$, Surekha Tayade ${ }^{2}$, Kiran Dhurve ${ }^{3}$ \\ 1, 2,3 Department of Obstetrics and Gynaecology, Jawaharlal Nehru Medical College, Datta Meghe Institute \\ of Medical Sciences (Deemed to Be University), Sawangi Meghe, Wardha, Maharashtra, India.
}

\section{INTRODUCTION}

Torsion of a pelvic organ presents as an acute emergency, most common being ovarian torsion. Uterine torsion in non-gravid uterus may occur but is a rare entity. Women presenting with severe and sudden pelvic pain to emergency department should prompt an assessment of torsion.

The pain of torsion may be described as intolerable due to ischaemic and compressive nature of the process. Women may also present with mild to severe pain accompanied with shock. Even though ovarian torsion is the most common, pedunculated fibroids leading to torsion have also been seen. Doppler imaging can display signs of decreased colour flow, reflective of ischemia or necrosis in ovarian torsion, which aids in diagnosis. Uterine torsion is uncommon and has often been reported with gravid uterus. Reported cases of leiomyoma presenting as uterine torsion is extremely rare.

\section{PRESENTATION OF CASE}

A 40-year-old woman, with three living children came to the emergency department with complaints of sudden and acute lower abdominal pain. She had a history of lump in abdomen for 6 months which was tender on examination. She identified the pain as sharp, severe and radiating to the right shoulder and neck, with nausea and diaphoresis associated with it. 1,2,3,4,5,6

The patient also complained to have a feeling of bloating in the past years with burning micturition and increased frequency of micturition for 6 months. She had no comorbidity. Menstrual abnormality was not noted.

On clinical presentation, the first approach to a patient is a medical history and physical examination. The patient seemed toxic and was unable to find any relief in pain with medication. On general examination, she was hypertensive with tachycardia. On per abdominal examination a mass corresponding to 26 weeks gravid uterus was felt. There was no guarding or tenderness. On bimanual examination a uterine mass was palpable. The patient felt pain, tenderness on palpation. Adnexal fullness was present but no adnexal mass was felt. $7,8,9,10$

\section{Diagnostic Evaluation}

Initial laboratory examination was done. Haemoglobin level was $10.7 \mathrm{gm} / \mathrm{dl}$ with no other significant findings on hematological parameters. Abdominal sonography confirmed large singular uterine mass of size approximately $12 \times 11 \times 8 \mathrm{~cm}$. However sonography did not indicate any evidence of torsion.
Corresponding Author: Dr. Sakshi Sharma,

Department of Obstetrics and Gynaecology, Jawaharlal Nehru Medical College, Datta Meghe Institute of Medical Sciences (Deemed to Be University), Sawangi Meghe, Wardha, Maharashtra, India.

E-mail:s.sakshisharma22@gmail.com

DOI: $10.14260 / \mathrm{jemds} / 2021 / 73$

How to Cite This Article:

Sharma S, Tayade S, Dhurve K. A twisted uterine mass - rare tale. J Evolution Med Dent Sci 2021;10(05):326-328, DOI: 10.14260/jemds/2021/73

Submission 28-09-2020,

Peer Review 21-11-2020,

Acceptance 28-06-2020,

Published 01-02-2021.

Copyright (c) 2021 Sakshi Sharma et al. This is an open access article distributed under Creative Commons Attribution License [Attribution 4.0 International (CC BY 4.0)] 


\section{DISCUSSION OF MANAGEMENT}

As the patient was hypertensive, medical stabilisation prior to surgical intervention was done with close monitoring. Then patient underwent exploratory laparotomy with hysterectomy and bilateral salpingo-oophorectomy.

\section{Surgical Intervention}

On entering the abdomen, $500 \mathrm{ml}$ of serosanguinous fluid was noted and aspirated. The uterus was described as bulky with fibroid of size $15 \times 15 \mathrm{~cm}$ occupying fundus and body of uterus acting as pivot to cause twisting of uterus (Figure 1). Uterus was partially twisted on its own axis, left ovary had twisted and was placed in the centre, more towards the right. Cervix was facing towards the left completely. The left round ligament was stretched and right one appeared shortened.11

After the hemoperitoneum was evacuated, uterus was seen to be levorotated and the torsion emerged at the level of junction between the cervix and uterine corpus. Hysterectomy was started after identifying the left round ligament, clamping and ligating it securely and step by step all the other pedicles were identified with a surgical precaution to prevent injury to the ureters (Figure 3). Intraoperatively blood transfusion was given and haemostasis was achieved and once stable, the patient was transferred to the post-operative unit. Postoperatively, the patient's course was uneventful and was discharged on post-operative day 10.

\section{PATHOLOGICAL DISCUSSION}

The mass was covered by a thin rim of pink serosa. The leiomyoma appeared approximately as a soft round mass weighing $1000 \mathrm{~g}$ and measuring $12 \times 7 \times 6 \mathrm{~cm}$. On pathological review leiomyoma appeared as a soft round mass weighing 1 Kg of size $12 \times 11 \times 8 \mathrm{~cm}$ approx. The serially sectioned specimen revealed a soft tan fleshy whirled intramural fibroid tissue of size $12 \times 13 \times 6 \mathrm{~cm}$. The ordinary spindled and epitheloid components were all marked with caldesmon, desmin, and smooth muscle actin.

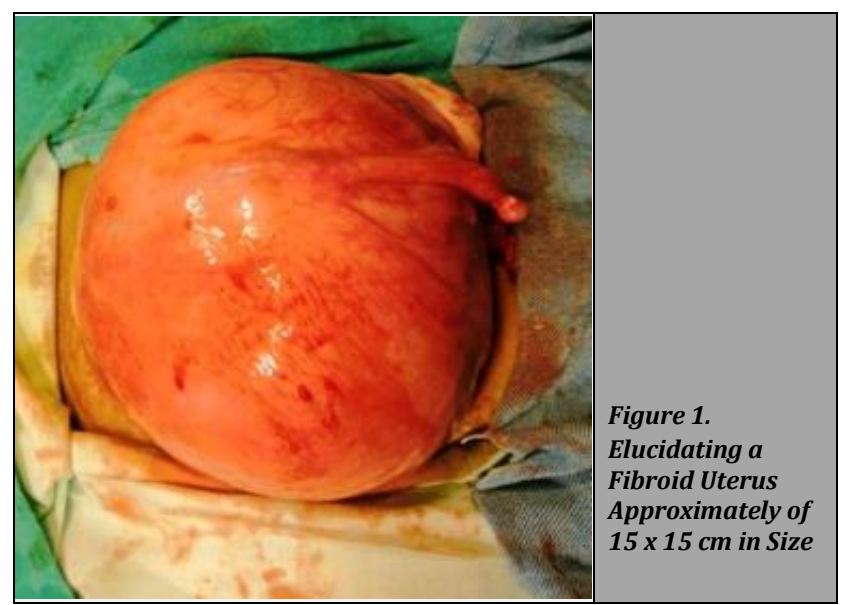

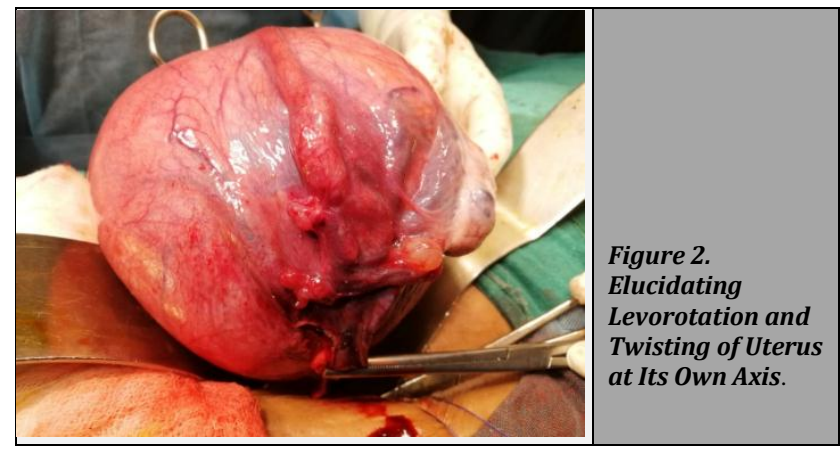
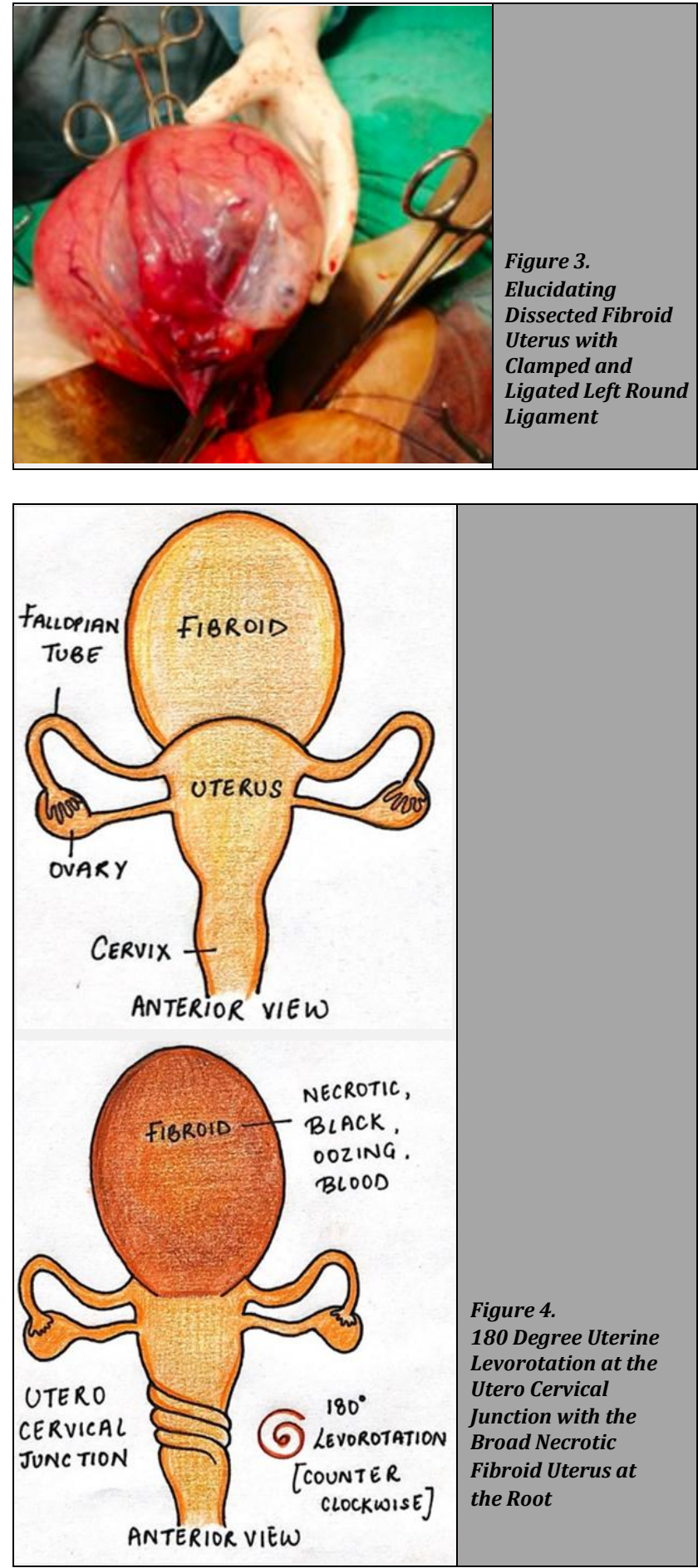
Uterine torsion refers to 45 degrees rotation of the uterus on its long axis, mostly occurring at the junction between the cervix and the uterine corpus ("A rare obstetric emergency: acute uterine torsion in a 32-week pregnancy | BMJ Case Reports," n.d.) (Figure 4).

Dextro-rotation is present in two third of cases. Torsion occurs because of weakness of parametrial tissue following menopause due to large mass.

Fibroids accompanied by uterine defects (bicornuate uterus), pelvic attachments, ovarian cysts or other adnexal mass, and irregular fetal appearance or fetal abnormality are the most common causes in the gravid uterus. (Piot et al., 1973).

The presentation is quite rare in nongravid uterus and ultrasonography or magnetic resource imaging is used for diagnosis (Dua, 2006; Hawes, 1935). Ultrasound result includes placental site and uterine leiomyoma transposition compared to previous scans and doppler identification of anterior uterine ovarian vessels. (Piot et al., 1973) Mostly, diagnosis is typically not made before surgical intervention (Dua, 2006; Havaldar and Ashok, 2014; Hawes, 1935; Qureshi et al., 2013; Sharma and Usha, 2013). In our case, surgical intervention was required for diagnosis of uterine torsion as imaging had failed to conclude diagnosis. A necrotising fibroid and pelvic malignancy were included in this patient's differential diagnosis, but not uterine torsion. This is a recorded case of uterine torsion in which leiomyoma was the causative process.

\section{CONCLUSIONS}

Pelvic organ torsion often occurs as sudden pain that does not respond to medication. Imaging and Doppler studies are used to confirm the diagnosis. Surgical intervention in such cases is often required. One should always rule out uterine torsion in a patient with an increasingly expanding fibroid uterus with acute pain.

Financial or other competing interests: None.

Disclosure forms provided by the authors are available with the full text of this article at jemds.com.

\section{REFERENCES}

[1] Moores KL, Wood MG, Foon RP. A rare obstetric emergency: acute uterine torsion in a 32-week pregnancy. BMJ Case Reports 2014;2014:bcr2013202974.

[2] Corr JE. Axial torsion of the gravid uterus in two successive pregnancies. American Journal of Obstetrics and Gynecology 1943;46(5):749-52.

[3] Dua A, Fishwick K, Deverashetty B. Uterine torsion in pregnancy: a review. The Internet Journal of Gynecology and Obstetrics 2006;6(1):1-3.

[4] Guié P, Adjobi R, N'Guessan E, et al. Uterine torsion with maternal death: our experience and literature review. Clin Exp Obstet Gynecol 2005;32(4):245-6.

[5] Hashimoto A, Takahama J, Harada N, et al. A case of uterine torsion concurrent with a ruptured ovarian endometrial cyst. Abdom Radiol (NY) 2016;41(9):170712.

[6] Havaldar N, Ashok K. Torsion of non-gravid uterus with ovarian cyst-an extremely rare case. Pan Afr Med J 2014;18:95.

[7] Hawes CH. Acute axial torsion of the uterus. Ann Surg 1935;102(1):37-40.

[8] Pierre C, Narducci F, Stien L. Torsion of a nongravid uterus: an unexpected complication of an ovarian cyst. European Journal of Obstetrics and Gynecology Reproductive Biology 2001;98(2):256-7.

[9] Piot D, Gluck M, Oxorn H. Torsion of the gravid uterus. Can Med Assoc J 1973;109(10):1010-11.

[10] Qureshi S, Singh U, Bansal B, et al. Torsion of preterm gravid uterus: a case report. International Journal of Case Reports and Images 2013;4(7):392.

[11] Sharma D, Usha MG. Torsion of a non-gravid uterus: a rare cause of acute abdomen. Int J Reprod Contracept Obstet Gynecol 2013;2(2):234-6. 